\title{
España, aparta de mí este cáliz, de César Vallejo: performance e Guerra Civil Espanhola
}

Carla Damêane Pereira de Souza Doutoranda em Letras - Literatura Comparada

\begin{abstract}
RESUMO
Por que um poeta peruano escreveu poemas que trazem como tema a Guerra Civil Espanhola? O objetivo deste ensaio é apresentar algumas questões relacionadas a essa indagação e as reflexões que foram feitas em torno da obra España, aparta de mí este cáliz, de César Vallejo.
\end{abstract}

\section{PALAVRAS-CHAVE}

Vallejo, poesia latino-americana, história, memória, performance

\section{INTRODUÇÃO}

O livro España, aparta de mí este cáliz, de César Vallejo, pode ser considerado distinto, em vários aspectos, de suas obras anteriores. Nessas obras antecessoras, Poemas en prosa e poemas humanos, (1923-1938), Trilce (1922) e Los heraldos negros (1918), César Vallejo expressava-se linguisticamente por meio de um projeto que, entre a ousadia de misturar temas relacionados à política marxista, estética do trabalho, niilismo, ou a morte, configurava certa busca por um sentido poético diante do ato da escrita. Em España, aparta de mí este cáliz (1939), Vallejo aproxima-se mais estreitamente das causas sociais, do sofrimento humano e o expressa relacionando-o com a Guerra Civil Espanhola (1936-1939).

Dos quinze poemas que compõem España, aparta de mí este cáliz (1939), entre os que estão datados, cinco foram escritos entre os meses de setembro e novembro de 1937. Há cerca de um ano havia começado a Guerra Civil Espanhola, e em abril de 1938 Vallejo morreria, ou seja, foram poemas escritos nos últimos meses que o poeta teve de vida. Nos poemas desse livro, o escritor transfere toda uma carga de reflexão e sofrimento, antes expressos de forma introspectiva, para o campo de uma prática retórica saturada de efeitos e emoções. Podemos 
utilizar o termo "sufrimiento armado," que Júlio Vélez ${ }^{1}$ cunha para denominar a projeção e dinâmica de um sofrimento que parte do individual até o universal na poética do livro aqui mencionado e justificado por causas explicáveis: a guerra, a injustiça, a morte sacrifical, a luta por um ideal utópico possível no campo da prática política aliada aos propósitos revolucionários da Guerra Civil Espanhola.

Entre tantos arquivos da Guerra Civil Espanhola que foram resgatados nesses últimos setenta anos de sua ocorrência, España, aparta de mí este cáliz (1939), do poeta peruano César Vallejo, constitui-se como um resto que faz parte das memórias extraoficiais. Um arquivo dentre outras manifestações que não podemos dizer que foram realizadas com intuito de resistir ao esquecimento, mas que são hoje em dia tratados por pesquisadores e historiadores como documentos que trazem conhecimentos sobre variadas versões e discursos da história em questão. Por tratar-se de um arquivo, España, aparta de mí este cáliz (1939), um livro composto de poemas escritos no contexto de um evento histórico (segundo minha leitura), avalia movimentos e sensações reconstituídas e presentifica memórias - de quem escreveu e daqueles que ali estão inscritos.

Para mim, existe, em España, aparta de mí este cáliz (1939), uma expressão performática que se dá por meio de uma capacidade poética, apoia-se ao referente histórico como recurso de instância flexível cuja verticalidade é sublinhada através das impressões e dos registros de movimentos que na obra se encontram presentes: a fascinação pela morte, a idealização de um herói épico, os hinos de homenagem aos voluntários, prognósticos de que a

\footnotetext{
${ }^{1}$ Na presente edição crítica organizada por Julio Vélez, César Vallejo: poemas en prosa, poemas humanos, España, aparta de mí este cáliz, referente à nota ao pé de página, o pesquisador, no poema "Voy hablar de la Esperanza", de Poemas em prosa, aponta que o poeta, quando escreve que sua dor carece de motivos, não possui qualquer explicação: "Me duelo ahora sin explicaciones”. (VÉLEZ. César Vallejo: poemas en prosa, poemas humanos, España, aparta de mí este cáliz, p. 99.) Assim, Vallejo demonstra-se preocupado por entender as causas do sofrimento humano. No Entanto, a apresentação desta dor se faz por meio de uma retórica abstrata. Em España, aparta de mí este cáliz ocorre uma mudança dessa retórica. Segundo Vélez (César Vallejo: poemas en prosa, poemas humanos, España, aparta de mí este cáliz, p. 99) a conclusão é que essa dor abstrata presente em seu poemário de guerra pode ser lida pela metáfora "sufrimiento armado", ou seja, decorrentes de motivos ou problemas que podem ser solucionados. Vélez aponta algumas ideias sobre o poema IV dessa obra. Nesse poema, para falar da Guerra Civil Espanhola, Vallejo constrói um mundo habitado por mendigos, soldados, guerreiros, proletários, gente que na luta cotidiana são livres de algo que ele chama no texto de "sofrimento antigo" (VÉLEZ. César Vallejo: poemas en prosa, poemas humanos, España, aparta de mí este cáliz, p. 264), como as reflexões existenciais metafísicas exploradas pela filosofia. Aos homens que lutam na Guerra Civil espanhola, ou que sobrevivem nas grandes cidades “Londres, New York, Méjico” (VÉLEZ. César Vallejo: poemas en prosa, poemas humanos, España, aparta de mí este cáliz, p. 264), diante deles, o poeta atinge uma retórica que compreende as causas de um sofrimento exteriorizado na imagem da miséria, da guerra, do exílio. É quando "o poeta saúda ao sofrimento armado”. (VÉLEZ. César Vallejo: poemas en prosa, poemas humanos, España, aparta de mí este cáliz, p. 265.)
} 
República cairia e paráfrases de orações. Tudo isso demonstra sua relação com a escrita da memória, mas sempre por meio das apropriações efetivadas a partir de referências à guerra nomes reais das cidades espanholas, descrição das batalhas, alusão a soldados que de fato lutaram na guerra, personagens da cultura hispânica, além da referência a si próprio.

A obra España, aparta de mí este cáliz (1939) pode ser interpretada como arte literária constituída por um forte traço autobiográfico. Esse traço está sustentado pela presença de informações sobre os textos críticos e jornalísticos escritos por César Vallejo e pela sua participação no II Congresso Internacional de Escritores Antifascistas em 1937. Na obra encontra-se uma característica de ordem performática produzida tanto pela relação do escritor com a política, como estratégia de intervenção no quadro social junto à opinião pública, quanto pelo engajamento estético dos poemas.

No caso de César Vallejo, ele transitou entre dois campos culturais distintos - arte e política -, durante uma época em que assumir determinadas posições era importante, sobretudo diante das polêmicas discussões que então dinamizavam o circuito artístico e político nas décadas de 1920 e 1930. Isto é, os artistas eram chamados de intelectuais em seu sentido político quando possuíam determinado grau de privilégio na arena pública, e decidiam utilizar esse privilégio articulando e expondo opiniões sobre assuntos atrelados aos interesses coletivos ou veiculados à sua prática artística.

Durante a década de 1920, Vallejo havia participado ativamente dos círculos culturais limenhos, em que se podia discutir sobre os problemas sociais peruanos. Afastado por conta de um exílio, após ter vivido a experiência da prisão política, Vallejo dirigiu a si mesmo uma missão: ser porta-voz da história de seu tempo em termos globais, expandido ainda mais seu engajamento à causa marxista. Seu contato com a realidade peruana e latino-americana, posteriormente com o mundo europeu, e com a experiência da revolução soviética de 1917, deu-lhe condições para retratar em verso e prosa a condição do homem daquela época junto ao seu momento histórico. O interesse de César Vallejo pela Segunda República Espanhola foi acompanhado pela fé do poeta diante das possibilidades de transformações políticas imediatas frente a situações nas quais o homem sofre algum tipo de exploração.

O compromisso de César Vallejo com a história, especificamente frente aos conflitos de origem política, são destaques em toda a sua trajetória como escritor, mas é pertinente avaliar como na década de 1930 esse compromisso desencadeou projetos de escritas em que o fator político, em termos partidários, se efetivava de maneira mais clara e objetiva. A escrita de España, aparta de mí este cáliz (1939) elucida bem essa trajetória biográfica, pois, em seu conjunto, constitui-se principalmente de um diálogo estreito com a história e a recusa à 
guerra.

\section{ASPECTOS TEÓRICOS E ANALÍTICOS}

Paul Ricœur, em A memória, a história, o esquecimento (2007), nos lança a seguinte pergunta: "que diferença separa a história e a ficção, se ambas narram?”2 O autor segue seu raciocínio estabelecendo uma relação entre a narrativa histórica junto ao que denomina como “aporia da verdade”. 3 A “aporia da verdade”, na história, encontra-se nas tentativas dos historiadores em construir uma narrativa da história a partir de pontos de vistas diferentes. Por ela, se concebem várias versões complementares, ou mesmo opostas, acerca de algum evento histórico narrado por diversas vezes e por historiadores diferentes. No entanto, para Ricœur, haveria uma possibilidade dessa “aporia da verdade” ser conjurada "se pudéssemos acrescentar umas às outras as versões sobre uma determinada história, mesmo que isso implicasse submeter as narrativas propostas às correções apropriadas”. 4

A partir desse raciocínio, pensa-se que, na impossibilidade de a narrativa histórica captar por inteiro as especificidades de um acontecimento, a narrativa ficcional aproxima-se também de uma escrita da história pelo viés estético. Os acontecimentos narrados em España, aparta de mí este cáliz (1939), pela forma com que estão dispostos na narrativa lírica, trazem a sua “aporia da verdade”, que para Ricœur poderia ser entendida como uma pulsão que se faz compreendida no trabalho da narração. Se para ele aparece como um questionamento: “dir-seá que é a vida, que presumivelmente tem a forma de uma história, que confere a força da verdade à narrativa enquanto tal?”, 5 em España, aparta de mí este cáliz (1939) a narrativa da história da Guerra Civil Espanhola nasce dentro de uma história de vida, a do poeta César Vallejo, cuja autoria dos poemas pode ser considerada como o principal responsável pela projeção dessa “aporia da verdade” e pelo trabalho de confecção dos poemas ter-se efetivado a partir de um viés de escrita de suas memórias pessoais.

Em Paul Ricœur, ${ }^{6}$ também encontram-se as postulações que distinguem imaginação de memória. Ele explica que na imaginação é possível enxergar um “irreal”, uma imagem fabulada, poisa realidade se encontra em suspenso. Por outro lado, na memória existe um

\footnotetext{
${ }^{2}$ RICEUUR. A memória, a história, o esquecimento, p.253.

${ }^{3}$ RICEEUR. A memória, a história, o esquecimento, p. 23.

${ }^{4}$ RICEEUR. A memória, a história, o esquecimento, p. 254.

${ }^{5}$ RICEUUR. A memória, a história, o esquecimento, p. 254.

${ }^{6}$ RICEEUR. A memória, a história, o esquecimento.
} 
“real” anterior à imagem. Contudo, o autor aponta ser um traço comum tanto na imaginação quanto na memória, “a presença do ausente”, 7 e afirma ser possível estabelecer uma linha que as una, isto é, no caso de operações historiográficas do passado, que tornem identificáveis estas conexões entre memória e imaginação. Trata-se da "lembrança-imagem”. ${ }^{8}$

A partir dessa teoria sobre a "lembrança-imagem", entende-se que o sujeito, a fim de narrar um determinado episódio passado, conjuga imaginação e memória e expõe a partir da construção de uma imagem sua, tanto o que deteve enquanto "real” quanto o que está anterior a esse "real”. Primeiramente, pensa-se em alguns poemas de España, aparta de mí este cáliz (1939), nos quais as imagens de morte em combate são narradas liricamente e presentifica o momento de tombo de um soldado como se fosse uma "lembrança-imagem" do acontecimento. Para que se possa compreender a expressão que Paul Ricœur utiliza para denominar as tentativas de representações do passado pela história, traremos à nossa reflexão um outro tipo de "lembrança-imagem” - a imagem fotográfica.

Nos anos da Guerra Civil Espanhola (1936-1939), muitos artistas internacionais se envolveram com a causa, e entre eles estava o fotografo húngaro Robert Capa, que apresentou ao mundo uma imagem "real” captada durante a Guerra Civil Espanhola. Trata-se da foto "O Soldado Tombando”. Feita no front de Córdoba em 1936, esta fotografia além de ter dado fama internacional a Capa, tornou-se referência obrigatória nos livros de história que abordam o assunto. Na imagem, o miliciano tomba para trás com os braços abertos para os lados, deixando seu fuzil cair e parece estar ferido de morte:

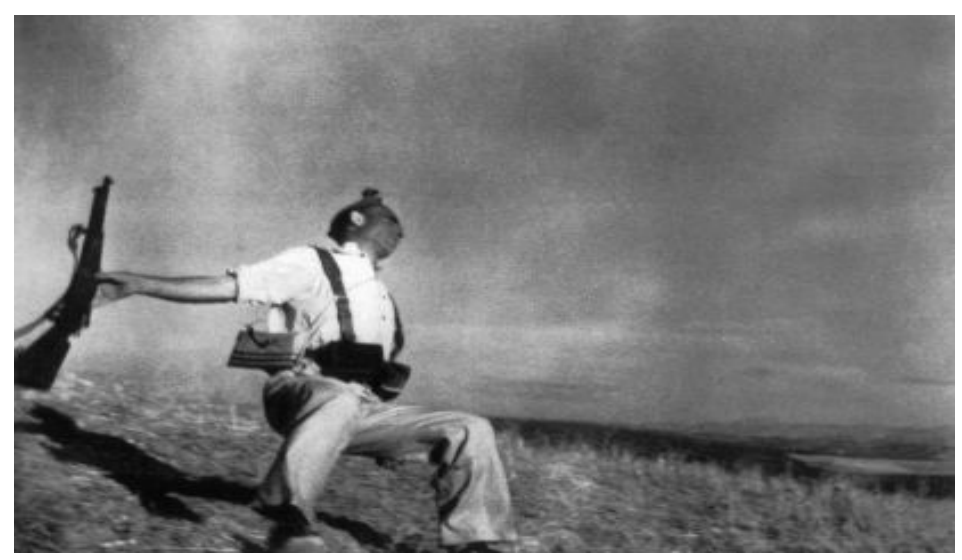

Figura 1 - Soldado Tombando de Robert Capa ${ }^{9}$

\footnotetext{
${ }^{7}$ RICEEUR. A memória, a história, o esquecimento, p. 61.

${ }^{8}$ RICCEUR. A memória, a história, o esquecimento, p. 61.

${ }^{9}$ Disponível em: <http://members.fortunecity.es/jberruezo3/fotos5.htm>.
} 
Em contraponto, o poema “Cortejo tras la toma de Bilbao”, de César Vallejo, traz a seguinte descrição sobre a notícia da morte de um soldado:

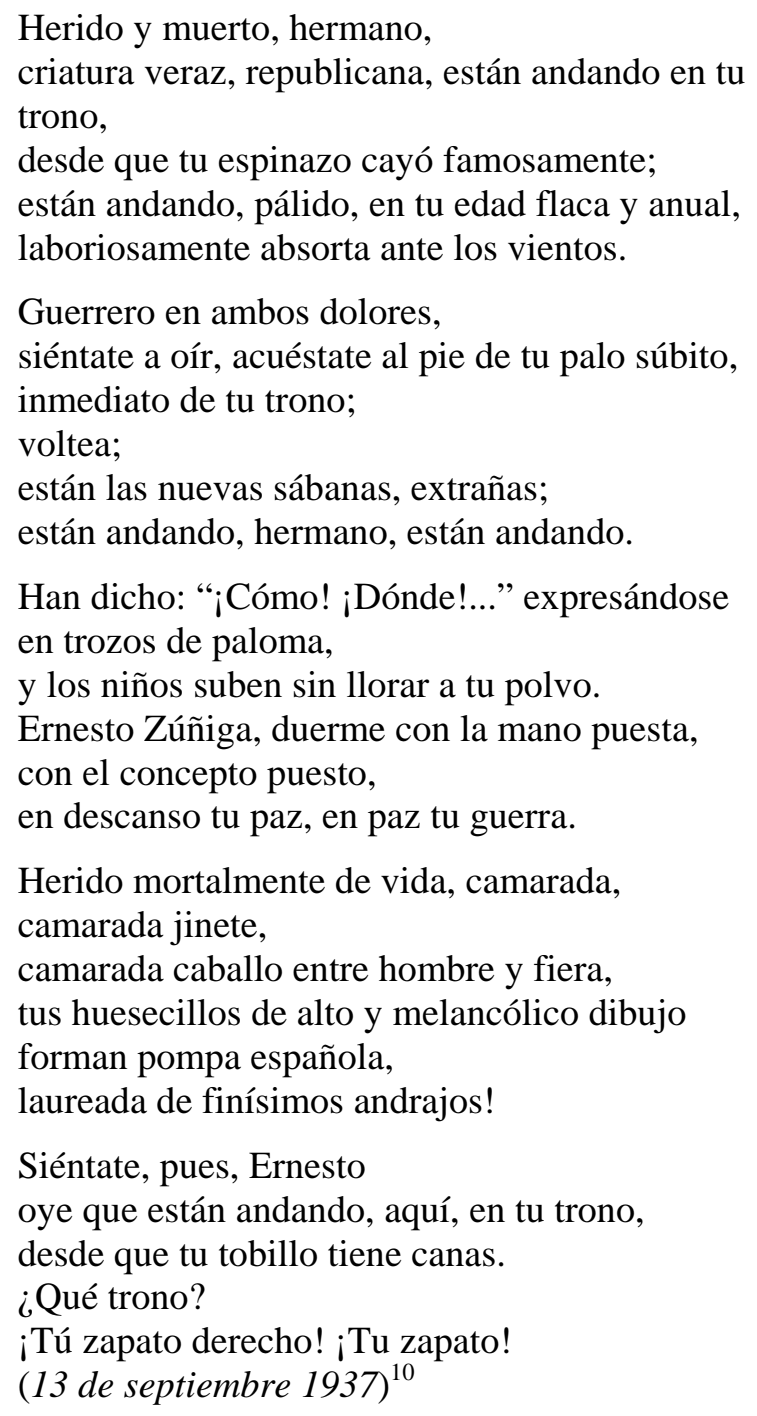

Importa dizer que a fotografia de Capa traz a identificação “verdadeira” do miliciano momento antes de ser atingido em combate. Ele havia sido fotografado junto a outros de seus companheiros. O soldado chamava-se Federico Borrel, fazia parte da Milícia de Alcoy e não se sabe, de fato, se o seu tombo foi mortal. Mesmo assim, Federico, imortalizado na foto de Capa, converteu-se em imagem de coragem e sacrifício diante da empreitada de militar e lutar na Guerra Civil Espanhola.

A tentativa de confrontar "lembranças-imagens" das memórias da Guerra Civil Espanhola faz-se conduzida pelo tema da morte apresentado na foto de Robert Capa; para chegar ao fato conclusivo - a morte do soldado - passa-se pela anterior narração de outras

\footnotetext{
${ }^{10}$ VÉLEZ. César Vallejo: poemas en prosa, poemas humanos, España, aparta de mí este cáliz, p. 269-
} 270. 
lembranças nas quais o soldado figura-se como aquele cuja trajetória de vida deve ser reconhecida. A fotografia de Capa, supomos que tenha sido vista por César Vallejo, e por isso assume função de uma “lembrança pura”. Posteriormente, essa lembrança foi posta em imagem através da ficcionalização da trama e do enredo que traz Ernesto Zúñiga como seu protagonista. O soldado fictício de Vallejo pode ser o mesmo soldado "real” cujo drama é apresentado na fotografia. Ambos são milicianos republicanos e sua individualidade, marcada pelos nomes próprios, identifica-os frente a uma legião de outros combatentes e reforça o papel de mártires na história.

Nos dois exemplos, embora a descrição da "lembrança-imagem” e recordação estejam isolados no contexto, são eles quem fazem o recorte ou a evocação de uma lembrança particular e, desse modo, "posta na via da oralidade, a rememoração também é posta na via da narrativa, cuja estrutura pública é patente”. ${ }^{11}$ Assim, a lembrança passa pelas categorias do individual, na esfera do si em relação àquele que busca ou recorda algo.

España, aparta de mí este cáliz (1939), em sua qualidade arquivística, foi escrito durante um momento de crise; apresenta uma assinatura pessoal de seu criador, um artista comprometido e preocupado com as questões políticas pelas quais a Espanha passava. Em cada poema existe uma história, imagens e emoções irrepresentáveis só passíveis de significação e projeção mediante talento e envolvimento profundo com a causa. Conforme afirma Seligman-Silva, ${ }^{12}$ pode-se entender que pelo testemunho ficcional Vallejo tenta "dar uma forma ao real”, atribuindo referencialidade a si mesmo a ao evento histórico que se propunha narrar. Trata-se de um tempo interior que, apesar de escapar ao registro como se referiu Casullo, ${ }^{13}$ deixa projeções assimiláveis aos sentimentos e à comunicação, por isso seria restringir a obra e tratá-la como simples arquivo disposto a adormecer. Deve conferirlhe, portanto, status de um testemunho que oferece ao leitor credibilidade, quanto ao compromisso com a história, por parte de quem está registrando que é César Vallejo.

Diante disso, crê-se ter encontrado um conceito pertinente para considerar España, aparta de mí este cáliz como arquivo. No entanto, como arquivo performático. Ou melhor, dizendo nas palavras de Graciela Ravetti, ${ }^{14}$ um transarquivo. Caberia a esse arquivo performático convocar uma assinatura autoral:

\footnotetext{
${ }^{11}$ RICEUUR. A memória, a história, o esquecimento, p. 139.

${ }^{12}$ SELIGMAN-SILVA. História, Memória, Literatura: o testemunho na Era das Catástrofes, p.376

${ }^{13}$ CASULLO. Pensar entre épocas. Memoria, sujetos, e crítica intelectual, p. 9.

${ }^{14}$ RAVETTI. Performances escritas: o diáfono e o opaco da experiência.
} 
A assinatura performance seria o que diferencia essas práticas performáticas - das demais; a consignação entrega-se a quem se responsabiliza por essa performance: como executante, como observador, como testemunha, como teórico, como crítico ou cumprindo mais de uma dessas funções. O consignante compromete seu corpo ou sua mirada (que é também seu corpo) e projeta-se naquilo que executa. ${ }^{15}$

Esse arquivo não está passível de se desligar daqueles que os puseram ao mundo, pois o que lhe confere vida e agitação deve-se, justamente, a projeção do que diz, por que diz e por quem o disse. Além disso, porque traz, conforme explica Ravetti, toda uma configuração coletiva, proporcionando a projeção de uma história ampla a partir de uma atitude micro, que parte de si. Adormecer implica não provocar, não fazer emergir quaisquer sensações por parte de quem com esse arquivo estabelece uma relação de troca. O transarquivo, pelo contrário, vem provocar uma experiência de alteridade.

Diana Taylor ${ }^{16}$ também faz considerações sobre a condição particular de um arquivo, que corpora um saber que excede o vivo, quando se constitui da materialidade daquilo que nele permanece registrado. Com relação ao repertório, Taylor explica que, ele excede o arquivo porque se relaciona à memória viva do corpo. Taylor chega a uma tese final e desembaraça o que pode ser entendido como uma relação antagonista entre arquivo e repertório, pois ambos são marcados pela performance. Diz:

A performance constitui-se, paradoxalmente, tanto pelo desaparecimento como pelo reaparecimento. Novamente, seria simplório pensar a performance como sendo de alguma forma corporificada e liberadora em oposição a um arquivo não-performático e hegemônico. O arquivo, assim como o repertório, está repleto de performances verbais - algumas que desaparecem outras que evocam, outras que inventam seu próprio objeto de inquirição. ${ }^{17}$

Considera-se que, na proposta poética de Vallejo em España, aparta de mí este cáliz (1939), o modo com que a inscrição da história faz-se nesse arquivo - transarquivo - é demonstrada pela performance verbal, que “evoca” e "inventa” ações e movimentos que se relacionam com o evento descrito - a Guerra Civil Espanhola. César Vallejo encena - por vias deste “evocar” e “inventar” - uma memória social e coletiva ficcionalizada, cujo traço arquivado infere uma projeção comunicativa, tal como se fosse um testemunho “real”. Além dos procedimentos operados pelo poeta, as subjetividades pessoais são importantes, e se deve a elas parte de um saber que nos chega por meio da leitura.

\footnotetext{
${ }^{15}$ RAVETTI. Performances escritas: o diáfono e o opaco da experiência, p. 38.

${ }^{16}$ TAYLOR. Encenando a memória cultural social: Yuyachkani.

${ }^{17}$ TAYLOR. Encenando a memória cultural social: Yuyachkani, p. 26.
} 
Penso que o procedimento escritural de España, aparta de mí este cáliz (1939), utilizado por César Vallejo, traz características de um texto apto à encenação. A significação dos sentidos explorados nos poemas desenha uma cena que, idealizada no campo ficcional, faz-se projetada como que a reencenar um momento que, de fato, o poeta poderia ter assistido, como observo neste poema:

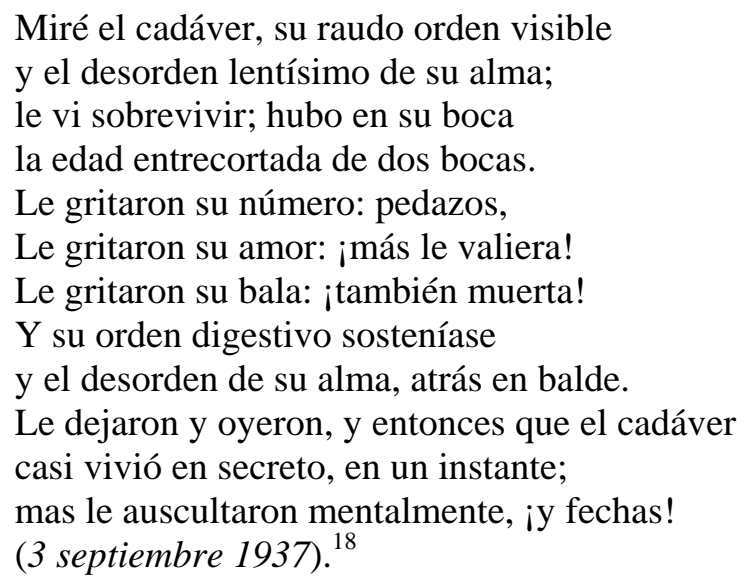

Além disso, chamo atenção aos prognósticos que Vallejo inferiu na escrita do Poema VII de España, aparta de mí este cáliz (1939), entre outros. Não havia este pressentimento quanto ao destino da República na carta que César Vallejo escreveu a Juan Larrea no dia 22 de janeiro de 1937. Pelo contrário, as impressões de Vallejo eram otimistas. Leia-se o trecho:

De España traje una gran afirmación de fe y esperanza en el triunfo del pueblo. Una fuerza formidable en los hombres y en la atmósfera. Desde luego, nadie admite ni siquiera en mientes, la posibilidad de una derrota. Desde ese punto de vista revolucionario los pasos se que se han dado son aún más halagadores. ${ }^{19}$

Nesse momento o principal objetivo é reverenciar esse sentimento “desde un punto de vista revolucionario” e mesmo a existência desse mau presságio presente nos poemas, pois o poeta ainda assim tenta edificar o que havia de utopia pela metaforizacão da escrita, como se fosse corpo, resto e ruína em seu poema "Pequeño responso a héroe de la República”:

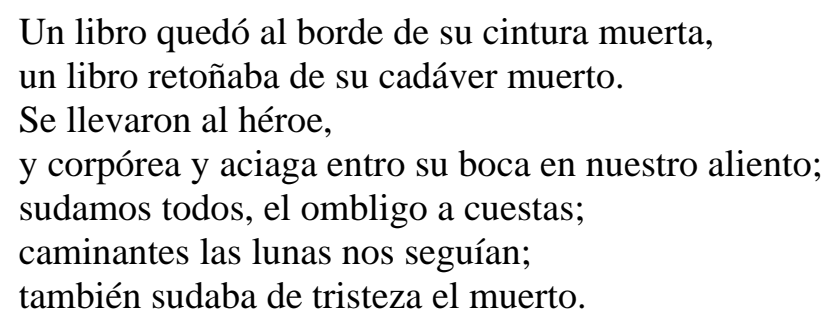

\footnotetext{
${ }^{18}$ VÉLEZ. César Vallejo: poemas en prosa, poemas humanos, España, aparta de mí este cáliz, p. 280.

${ }^{19}$ VALLEJO. Escritos en prosa, p. 197.
} 
Y un libro en la batalla de Toledo,

un libro, atrás un libro, arriba un libro, retoñaba del

cadáver.

Poesía del pómulo morado, entre el decirlo

y el callarlo,

poesía en la carta moral que acompañara

a su corazón.

Quedóse el libro y nada más, que no hay

insectos en la tumba,

y quedó al borde de su manga el aire remojándose,

y haciéndose gaseoso, infinito.

Todos sudamos, el ombligo a cuestas,

también sudaba de tristeza el muerto

y un libro, yo lo vi sentidamente,

un libro, atrás un libro, arriba un libro

retoñó del cadáver exabrupto.

(10 septiembre 1937$)^{20}$

Sobre esse poema, uma leitura interessante está em "La hermenéutica vallejiana y el hablar materno” (1988), de Julio Ortega. O estudioso chama a atenção para a concepção de livro em "Pequeño Responso a un Héroe de la República”. Ela pode ser entendida como um paradigma plural da República em armas, porque "una verdadera arqueología del discurso podría establecerse, para demonstrar que en esta discursividad del poema se levanta como una página él mismo que retoña del cuerpo discursivo español”. ${ }^{21}$ A conversão da morte em livro que se faz de forma volátil "fazendo-se gasoso, infinito”, segundo minha leitura, demonstra a reconstrução de um ideal que se converte em mundo pela forma de livro-ar, ou livro-corpo. Trata-se de um testemunho no qual não há sobrevivente, mas um livro que resulta da experiência ficcional exteriorizada pela linguagem, na tentativa de expor para o plano "real” histórias não vividas. Se no poema o livro-corpo é a testemunha do fato histórico, para a história é España, aparta de mí este cáliz (1939) o testemunho de César Vallejo.

\section{CONCLUSÃO}

A crença de escritor na execução e defesa de um projeto político, como foi a Segunda República Espanhola, é um dos elementos que compõe seu livro. Nessa mesma escrita, os sinais de fé se dispersavam dia após dia, com a queda de mais uma cidade, com a morte de mais um homem, cujo gozo futuro é ver-se transfigurado em um livro consumido pelo ar. De toda forma, não se abstrai em si mesmo o autossacrifício. A ressurreição transforma o corpo

\footnotetext{
${ }^{20}$ VÉLEZ. Julio. César Vallejo: poemas en prosa, poemas humanos, España, aparta de mí este cáliz, p. 276-277.

${ }^{21}$ ORTEGA. La hermenéutica vallejiana y el hablar materno, p. 619.
} 
em mundo. Livro-corpo que volta a habitar entre os iguais (outros soldados) diante da história não regressiva, e sim, sempre atenta a aproximar o que dela resta, àqueles que para ela olham. No entanto, a história não se permite a paralisia, e dessa maneira, seu constante movimento trará sempre de volta livros e cadáveres que se julgavam esquecidos pela humanidade. Algo parecido acontece com España, aparta de mí este cáliz, que foi abordado neste estudo, o qual se insere numa pesquisa maior.

Entendo que os debates recentes que acontecem na Espanha surgem como sinal de que o tempo não submerge frente à história. ${ }^{22}$ Não importa o que haja, porque sempre haverá alguém que tapará os ouvidos e os olhos frente a ferida escancarada da injustiça; ou outros que, legitimados, distribuirão as vendas e os fones. O escândalo que o Bombardeio de Guernica causou, em 1937, não evitou o escândalo causado pelos ataques a Hiroshima e Nagasaki de 1944, que não evitou o Napalm destruindo as comunidades de vietnamitas durante a Guerra da Indochina, que não evitou os campos de refugiados em Kosovo, que não evitou o 11 de Setembro, que não evita até hoje, que haja injustiça, repressão e terror de um povo contra outro, ou, de um povo contra o seu próprio povo.

Nas situações onde o homem não é capaz de denunciar, transformar, de subverter um estado de crise questionando-o a fim de evitar a violência, España, aparta de mi este cáliz revive uma possibilidade, um ideal, durante uma realidade bélica na qual a morte significava vantagem para o inimigo, por isso ressuscitar é resistir, sobreviver é resistir, reescrever a história é resistir como ressurreição do ideal de ainda querer mudança na cena política e social mesmo que pela morte transformada em performance política e individual daquele que se entrega, seja o soldado, ou o escritor, César Vallejo.

\section{RESUMEN}

¿Por qué un poeta peruano escribió poemas que traen como tema la Guerra Civil Española? El objetivo de este ensayo es presentar algunas cuestiones relacionadas a esta indagación y a las reflexiones que fueron hechas cerca de la obra España, aparta de mí este cáliz, de César Vallejo.

\section{PALABRAS-CLAVE}

Vallejo, poesía latino-americana, historia, memória, performance

${ }^{22}$ Ver: “Asociación para la recuperación de la memória histórica”. Site eletrônico disponível em: $<$ http://www.memoriahistorica.org/index.php>. Acesso em: 12 jul. 2009. 


\section{REFERÊNCIAS}

CAPA, Robert. 1936. 1 foto. "Robert Capa (1913-1954) y sus mejores fotos en la línea del frente." Grupo de Historia. José Berruezo. <www.jberruezo.cjb.net> Disponível em: $<$ http://members.fortunecity.es/jberruezo3/fotos5.htm> Acesso em 12 jun. 2009.

CASULLO, Nicolás. Pensar entre épocas. Memoria, sujetos, e crítica intelectual. Buenos Aires: Grupo Editorial Norma, 2004.

ORTEGA, Julio. César Vallejo y la Guerra Civil Española. Instituto de Estudos Vallejianos. Brigham Young Universt, 2002. Disponível em: <http://spanport.byu.edu/instituto_vallejiano/articulohtml/dovcuments/cesar_vallejo_3pdf>. Acesso em: 30 abr. 2008.

ORTEGA, Julio. La hermenéutica vallejiana y el hablar materno. In: FERRARI, Américo. (Org.). César Vallejo obra poética. Edición Crítica. España: Colección Arquivos, 1988. p. 607-620.

RAVETTI, Graciela. Narrativas performativas. In: RAVETTI, Graciela; ARBEX, Márcia (Org.). Performance, exílio, fronteiras. Errâncias territoriais e textuais. Trad. Melissa Boechat e Karla Cipreste. Belo Horizonte: Departamento de letras românticas, POSLIT/FALE/UFMG, 2002. p. 45-68.

RAVETTI, Graciela. Performances escritas: o diáfono e o opaco da experiência. In: HIDELBRANDO, Antônio; NACIMENTO, Lisley; ROJO, SARA (Org.). O corpo em performance, texto e palavra. Trad. Melissa Gonçalves Boechat e Karla Fernandes Cipreste. Belo Horizonte: Núcleo de estudos em letras e artes performáticas / FALE/UFMG, 2003. p. 29-61.

RAVETTI, Graciela. Notações espaciais como forma de inteligibilidade cultural. Graciliano Ramos, José Maria Arguedas, Juan Jose Saer. In: ALEXANDRE, Marcos Antônio et al. (Org.). Caligrama, Revista de Estudos Românticos. Belo Horizonte, v. 10, p. 183-207, dez. 2005.

RICEEUR, Paul. A memória, a história, o esquecimento. Trad. Alain François et al. Campinas: Editora Unicamp, 2007.

ROJO, Sara; VECCHI, Roberto. Dialogando à margem da representação. In: (Org.). Transliterando o Real: diálogos sobre as representações culturais entre pesquisadores de Belo Horizonte e Bologna. Belo Horizonte: Faculdade de Letras da UFMG, 2004.

SELIGMANN-SILVA, Márcio (Org.). História, memória, literatura: o testemunho na Era das Catástrofes. Campinas: Ed. Unicamp, 2003.

SELIGMANN-SILVA, Márcio. O local da diferença: ensaios sobre memória, arte, literatura e tradução. São Paulo: Ed. 34, 2005.

TAYLOR, Diana. Encenando a memória cultural social: Yuyachkani. In: ARBEX, Márcia; RAVETTI, Graciela. Performance, exílio, fronteiras: errâncias territoriais e textuais. Trad. Leda Martins. Belo Horizonte: Departamento de Letras Românicas, Faculdade de Letras/UFMG: Poslit, 2002.

TAYLOR, Diana. El espetáculo de la memória: trauma, performance política. Hemispheric Institute. Disponível em: <http://hemi.nuy.edu/archive/text/hijos2.html>. Acesso em: 22 ago. 2008. 
THOMAS. Hugh. A Guerra Civil Espanhola. Trad. James Amado e Hélio Polvora. Rio de Janeiro: Civilização Brasileira, 1964. v. 1.

THOMAS. Hugh. A Guerra Civil Espanhola. Trad. James Amado e Hélio Polvora. Rio de Janeiro: Civilização Brasileira, 1964. v. 2.

VALLEJO, César. Escritos en prosa. Buenos Aires: Losada, 1994.

VÉLEZ. Julio. César Vallejo: poemas en prosa, poemas humanos, España, aparta de mí este cáliz. Madrid: Cátedra, 2000. 